\title{
Neural transplants in spinal cord injury
}

\author{
J-C Horvat
}

\begin{abstract}
Professor, Director of the Research Group 'Transplantation and Repair of the Spinal Cord and of its Motor Connections', Laboratoire de Neurobiologie, Université René Descartes, 45 rue des Saints-Pères, 75270 Paris Cedex 06, France.
\end{abstract}

Spontaneous recovery from severe traumatic or neurodegenerative lesions of the central nervous system (CNS), which includes the brain and the spinal cord, does not occur in adult mammals because the lost neurons are not replaced; the surviving nerve cells do not regenerate the missing part of their cut axon. The likely reason for this is inhibitory effects from the mature glial cells: reactive astrocytes ${ }^{1}$ and differentiated oligodendrocytes. ${ }^{2,3}$ Conversely, lengthy axonal regrowth is known to take place in the peripheral nerves of adult mammals, as well as in the CNS of fishes and amphibians.

With regard to traumatic injury to the spinal cord, damage will result in an immediate loss of intrinsic spinal neurons as well as in axotomy of both intrinsic and extrinsic (projection) neurons. In turn, axotomized nerve cells may either die after a variable delay, or survive axotomy. Yet, the surviving axotomized neurons will not re-establish their original functional connections. For instance, severance of the corticospinal tracts and/or important loss in the motoneuronal pool will result in a functional disconnection between the 'upper motor neurons' and the skeletal muscles, thus causing chronic paralysis.

However, transplantation strategies that aim at repairing the injured mammalian CNS have been developed. Thus, to some extent: (1) lost neurons can be replaced by foetal nerve cells, ${ }^{4}$ grafted either as solid pieces of CNS tissue ${ }^{5,6}$ or as CNS cell suspensions; ${ }^{7,8}$ (2) axonal (re)growth and extension, from both host and transplanted neurons, can be triggered and guided by long segments of peripheral nerve autografts (PNGs). ${ }^{9,10,11}$

Several types of transplant are commonly used in animal experimentation aimed at spinal cord repair or reconstruction. They differ mainly by their nature and origin: foetal extraspinal (heterotopic) ${ }^{12-14}$ or spinal (homotopic) ${ }^{12,14,15}$ CNS tissue, autologous peripheral nerve $;^{11,14,16-20}$ but also by their mode of action: protective and/or trophic effect on the host neural tissue, ${ }^{12,15,16}$ inhibitory influence on glial reaction, ${ }^{12,21}$, guiding effect on axonal regrowth, $11,14,17-20$ and role of substitution. $8,14,15,18$

However, peripheral nerve autografts, used to join the 2 stumps of a completely transected spinal cord, are unable to promote any functional restoration as: (1) corticospinal axons do not regenerate into the grafted nerves; ${ }^{20}$ (2) axons originating from spinal or brain stem neurons may grow throughout the grafted nerves but their possible re-entry into the caudal stump of the host spinal cord is restricted to a few millimeters, ${ }^{20}$ suggesting that injured adult CNS tissue is a rather non permissive terrain for axonal growth and extension. Along the same lines, in less severe spinal injuries, surviving motoneurons will grow axons into $\mathrm{PNGs}^{11}$ as well as into reimplanted, ${ }^{22}$ but not into intact, ${ }^{23}$ spinal roots.

Taking all of these data into account, our research group in Paris $\mathrm{V}$ University is studying, in the adult rat, the possibilities of an anatomical and functional reconstruction of the injured spinal cord by means of the above mentioned transplantation techniques, used alone or in combination with molecules supposed to be active in reducing glial scarring, ${ }^{24}$ and/or in permitting axonal regrowth and extension. ${ }^{25,26}$ At present, emphasis is laid on the reconnection of the injured spinal cord with its peripheral motor effectors.

Several experimental models are being studied which correspond to different types of spinal severance (focal and mild lesion, without substantial neuronal loss; mechan- 
ical or chemical depletive lesions, involving important neuronal loss) and, consequently, to different ways of repairing the injured spinal cord (with or without foetal neural tissue).

In a first model, ${ }^{11}$ one end of an autologous PNG (a $30 \mathrm{~mm}$ segment of the common peroneal nerve), was introduced into the cervical spinal cord, thus determining a small and localised lesion which did not cause any apparent functional deficit. The other end of the PNG was inserted into an aneural area of a nearby skeletal muscle of the dorsal musculature, which was carefully denervated prior to grafting. After 2 to 21 months following surgery, it was noticed that the reconnected muscle contracted under an adequate electric stimulation of the nerve bridge.

Application of different axonal tracers (horse radish peroxidase $=\mathrm{HRP}$, fluorescent dyes) to the nerve bridge led to an extensive neuronal labelling in the whole spinal grey matter, between $\mathrm{C} 3$ and $\mathrm{C} 7$. Yet, when the tracers were injected directly into the muscle, the neuronal labelling was mainly restricted, in the same segments, to typical motoneurons of the ventral horn, different from those that normally innervate the experimental muscle (as they are located unilaterally in $\mathrm{C} 1$ and $\mathrm{C} 2$ ).

In the reconnected muscle, morphological studies revealed that motor endplates had been reformed not only at the sites of original innervation but also, and mainly, in ectopic locations all around the grafted nerve. These neuromuscular junctions were quite functional and necessarily formed by regenerated axons in the $\mathrm{PNG}$, as electrical stimulation of this graft triggered the contraction of the muscle to which it was attached. In addition, the reformed endplates were cholinergic insofar as the endplate potentials, evoked by the stimulation of the PNG, could be suppressed by the action of curare, added to in vitro preparations.

Thus was reformed a functional motor system of substitution which, however, appears anatomically far removed from the original model as its motoneuronal pool, the course of its motor axons and the sites of terminal innervation are different. In this sense, this experimental model constitutes an additional example of the remarkable plasticity of the adult mammalian central and peripheral nervous systems.

The studies concerning a second experimental model ${ }^{14}$ have been developed more recently. Their main objective is an attempt at repairing larger spinal lesions, implicating important neuronal loss. The last stage of this experimentation will consist in joining, by means of a PNG, a foetal neural transplant of substitution, designed to fill a cavity made by unilateral aspiration of the host grey matter and dorsal funiculi in $\mathrm{C5}$, and the muscle used in our first set of experiments. The studies carried out so far concern a preliminary stage where the distal end of the PNG, unconnected to the muscle, is made blind by crushing and stitching it to extraspinal tissues. Should the aspiration procedure be gentle enough, the resulting motor deficit is apparently restricted to paralysis of the right upper limb. The cavity is filled with solid pieces of neural tissue (cortex, spinal cord or dorsal root ganglia), removed from E13 to E18 inbred embryos.

From one to 6 months following the double transplantation, healthy appearance of the 3 types of transplants and integration with the host tissues were consistently observed. Surviving neurons in the grafted tissues developed processes, some of which became myelinated. Yet, the ability of the grafted neurons to extend axons into the PNG differed strikingly from one type of graft to another, being apparently non existent for cortical grafts, moderate for spinal cord grafts and quite extensive for dorsal root ganglia transplants. Interestingly, these differences reflected, at least in part, what was observed for the corresponding, fully differentiated neurons in adult animals when their cut axons were also placed in contact with the non neuronal components of peripheral nerves. In addition, some host spinal neurons, mainly located around the transplants, appeared HRP-labelled, indicating that they had also grown axons into the PNG.

Other models are being developed with external collaborations. For instance, kaïnic acid-induced cavitation lesions of the lumbar spinal cord have been filled with dissoci- 
ated foetal spinal cord tissue. ${ }^{18}$ A great number of grafted neurons did survive and some were shown to grow axons into blindended PNG.

Studies of the possibilities of all these neurons of substitution to form whatever connections with denervated skeletal muscles, as well as of their eventual reafferentation by regenerating central nerve fibres of the host, are in progress.

In conclusion, embryonic neurons and autologous peripheral nerve segments constitute selected materials for studying CNS plasticity and repair in adult mammals.
Transplanted to the brain or the spinal cord, the former are possible substitutes designed to replace lost or deficient host neurons while the latter have useful stimulating and guiding effects upon axonal regrowth from surviving axotomized neurons.

\section{Acknowledgements}

The studies carried out in our laboratory were supported by grants INSERM 886007 and 886010 , DRET 88-212 and IRME/AFM 1989-90.

\section{References}

1 Reier PJ, Eng LF, Jakeman L (1989) Reactive astrocyte and axonal outgrowth in the injured CNS: is gliosis really an impediment to regeneration? In: Seil FJ, ed. Neural Regeneration and Transplantation. Alan Liss, New York: 183-209.

2 Caroni P, Schwab ME (1989) Codistribution of neurite growth inhibitors and oligodendrocytes in rat CNS: appearance follows nerve fiber growth and precedes myelination. Dev Biol 136: 287- 295.

3 Schwab ME, Caroni P (1988) Oligodendrocytes and CNS myelin are non permissive substrates for neurite growth and fibroblast spreading in vitro. J Neurosci 8: 2381-2393.

4 Björklund A, Stenevi U (1984) Intracerebral neural implants: neural replacement and reconstruction of damaged circuitries. Ann Rev Neurosci 7: 279-308.

5 Das GD, Hallas BH (1978) Transplantation of brain tissue in the brain of adult rats. Experientia 34: 1304-1306.

6 Sunde NA, Zimmer J (1983) Cellular histochemical and connective organization of the hippocampus and fascia dentata transplanted to different regions of immature and adult rat brains. Dev Brain Res 8: 165-191.

7 Björklund A, Stenevi U, Schmidt RH, Dunnett SB, Gage FH (1983) Intracerebral grafting of neuronal cell suspensions. II Survival and growth of nigral cells implanted in different brain sites. Acta Physiol Scand (suppl) 522: 11-22.

8 Privat A, Mansour H, Geffard M (1988) Transplantation of fetal serotonin neurons into the transected spinal cord of adult rats: morphological development and functional influence. Prog Brain Res, 78: 155-166.

9 Aguayo AJ (1985) Axonal regeneration from injured neurons in the adult central nervous system. In: Cotman CW, ed. Synaptic Plasticity. Guilford Press, New York: 447-484.

10 David S, Aguayo AJ (1981) Axonal elongation into 'PNS' bridges after CNS injury in adult rats. Science 214: 933-935.

11 Horvat JC, Pécot-Dechavassine M, Mira JC, Davarpanah SY (1989) Formation of functional endplates by axons regenerating through a peripheral nerve graft. A study in the adult rat. Brain Res Bull 22: 103-114.

12 Bregman BS, Reier PJ (1986) Neural tissue transplants rescue axotomized rubrospinal cells from retrograde death. J Comp Neurol 244: 86-95.

13 Das GD (1983) Neural transplantation in the spinal cord of the adult mammal. In: Kao CC, Bunge RP, Reier PJ, eds. Spinal Cord Reconstruction. Raven Press, New York: 367-396.

14 Horvat JC, Baillet-Derbin C, Ye JH, Rhrich F, Affane F (1991) Co-transplantation of embryonic neural tissue and autologous peripheral nerve segments to severe spinal cord injury of the adult rat. Restor Neurol Neurosci 2: 289-298.

15 Houlé JD, Reier PJ (1988) Transplantation of fetal spinal cord tissue into chronically injured adult rat spinal cord. J Comp Neurol 269: 535-547.

16 Kao CC (1974) Comparison of healing process in transected spinal cord grafted with autogenous brain tissue, sciatic nerve and nodose ganglion. Exp Neurol 44: 424-439.

17 Kao CC, Chang LW, Bloodworth JBM (1977) Axonal regeneration across transected mammalian spinal cords: an electron microscopic study of delayed microsurgical nerve grafting. Exp Neurol 54: 591-615.

18 Nothias F, Horvat JC, Mira JC, Pécot-Dechavassine M, Peschanski M (1990) Double step neural transplants to replace degenerated motoneurons. In: Dunnett SB, Richards SJ, eds. Progress in Brain Research. Elsevier Science Publishers Amsterdam: 239- 246.

19 Richardson P, Issa VMK, Aguayo AJ (1984) Regeneration of long spinal axons in the rat. J Neurocytol 13: $165-182$. 


\section{Horvat}

20 Richardson P, McGuinness UM, Aguayo AJ (1982) Peripheral nerve autografts to the rat spinal cord: study with axonal tracing methods. Brain Res 237: 147-162.

21 Reier PJ, Bregman BS, Wujek JR (1986) Intraspinal transplantation of embryonic spinal cord tissue in neonatal and adult rats. J Comp Neurol 247: 275-296.

22 Carlstedt T, Linda H, Cullheim S, Risling M (1986) Reinnervation of hind limb muscles after ventral root avulsion and implantation in the lumbar spinal cord of the adult rat. Acta Physiol Scand 128: 645-646.

23 Risling M, Cullheim S, Hildebrand C (1983) Reinnervation of the ventral root L7 from ventral horn neurons following intramedullary axotomy in adult cats. Brain Res 280: 15-23.

24 Kupferberg A, Teller G, Behr P et al (1989) Effect of $7 \beta$-hydroxycholesterol on astrocyte primary cultures and derived spontaneously transformed cell lines. Cytotoxicity and metabolism. Bioch Biophys Acta 1013: 231-238.

25 Delpech A, Delpech B, Girard N, Bertrand P, Chauzy C (1987) Hyaluronectine and hyaluronic acid during the development of the rat brain cortex. In: Wolff JR, Sievers J, Berry M, eds. Mesenchymal epithelial interactions in neural development. Cell Biology 5: 77. Springer Verlag.

26 Gospodarowicz D, Neufeld G, Schweigerer L (1986) Fibroblast growth factor. Mol Cell Endocrinol 46: 187-204. 